\title{
Intramammary immunization with ultraviolet-killed Escherichia coli shows partial protection against late gestation intramammary challenge with a homologous strain
}

\author{
B. Pomeroy, ${ }^{* 1,2}$ A. Gurjar, ${ }^{* 2,3}$ A. Sipka, ${ }^{*}$ S. Klaessig, ${ }^{*}$ S. Salmon, $\dagger$ R. Quesnell, $\dagger$ and Y. H. Schukken ${ }^{*} \neq \S$ \\ *Department of Population Medicine and Diagnostic Sciences, College of Veterinary Medicine, Cornell University, Ithaca, NY 14853 \\ †Zoetis Animal Health, Kalamazoo, MI 49007 \\ ¥GD Animal Health, Arnsbergstraat 7, 7411 EZ Deventer, the Netherlands \\ §Department of Animal Sciences, Wageningen University, 6708 PB Wageningen, the Netherlands
}

\begin{abstract}
The objective of this study was to evaluate the efficacy of intramammary immunization with UV-killed Escherichia coli ECC-Z on prevention of intramammary colonization after a challenge with a dose of the homologous E. coli ECC-Z live bacteria. A total of 10 cows were included in a study to evaluate the efficacy of intramammary immunization. All 10 cows received an intramammary immunization of $100 \mathrm{cfu}$ of UV-killed $E$. coli ECC-Z bacteria into one hind quarter at the time of dry off. Approximately 2 wk before the anticipated calving date, both hind quarters of all cows were challenged with $100 \mathrm{cfu}$ of live E. coli ECC-Z bacteria. Five of the cows were vaccinated parenterally with a commercial J5 bacterin, and 5 cows served as controls with no parenteral vaccination. The cows were then followed over time and infection risk, clinical scores, somatic cell count, and milk production were observed over time. The results of these 10 cows showed partial protection of intramammary immunization on the outcome of a subsequent homologous intramammary challenge. Immunization resulted in a lower probability of infection, a lower bacteria count, lower somatic cell counts and milk conductivity, a lower clinical mastitis score, and increased milk production compared with unimmunized control quarters. Once the analysis was corrected for immunization, parenteral J5 vaccination had no significant effect on any of the measured parameters. These results provide the first evidence that intramammary immunization may improve the outcome of an intramammary E. coli infection in late gestation and onset of mastitis immediately following parturition. Unlike systemic vaccination, which generally does not
\end{abstract}

Received March 9, 2016.

Accepted August 2, 2016.

${ }^{1}$ Corresponding author: bjp62@cornell.edu

${ }^{2}$ Both authors contributed equally to this research.

${ }^{3}$ Current address: Merck Animal Health, Madison, NJ 07940. reduce the intramammary infection risk, the intramammary immunization did show a 5-times reduced odds of an established intramammary infection after challenge. Cytokine profiles indicated a local return of proinflammatory response after challenge as the data showed a more pronounced increase in in IFN- $\gamma$ with a subsequent negative feedback due to a spike in the level of IL-10 in immunized quarters relative to nonimmunized quarters. Although these results are preliminary and obtained on only 10 cows, the results provide insight into the biological benefits of triggering mucosal immunity in the mammary gland.

Key words: Escherichia coli, vaccination, mastitis, late gestation

\section{INTRODUCTION}

Clinical mastitis is one of the most common and costly challenges to the dairy industry (Gröhn et al., 2004). Approximately $40 \%$ of clinical mastitis cases are attributed to gram-negative, mostly coliform, bacterial infection (Barkema et al., 1998; Gröhn et al., 2004; Oliveira et al., 2012). Bovine coliform mastitis is generally considered to be caused by opportunistic infections (Bradley and Green, 2001), although evidence for a host-adapted subpopulation is growing (Bradley and Green, 2001; Dogan et al., 2006; Shpigel et al., 2008; Lippolis et al., 2014). The incidence of clinical mastitis peaks on most farms immediately following parturition (Barkema et al., 1998), although several observational and experimental challenge studies indicate the presence of the mastitis-causing bacteria isolated from the dry gland before parturition without clear inflammatory indicators of mastitis (Green et al., 2007; Quesnell et al. 2012). The late gestation challenge study using Escherichia coli ECC-Z by Quesnell et al. (2012) showed that cows in late gestation respond to challenge with an IL-10 dominated response and a minimal response of proinflammatory cytokines, such as IFN- $\gamma$ and IL$1 \beta$. This suggested shift toward a predominantly anti- 
inflammatory, highly regulated response during the dry period likely reflects an adaptation in maternal immune signaling during late gestation to protect the semiallogenic fetus (Quesnell et al., 2012; Pomeroy et al., 2015).

Dairy cows may be vaccinated parentally against coliform mastitis using a core J5 bacterin that has been repeatedly reported to reduce clinical severity of response to these infections (Hogan et al., 1992, 1995; Wilson et al., 2008). However, these vaccination studies have not shown a reduction in incidence of clinical coliform cases. Local immune responses are important for protection against pathogens that predominately infect and cause disease at mucosal sites. Mucosal vaccines have shown to be effective both in the case of viral (i.e., oral polio vaccine, intranasal infectious bovine rhinotracheitis vaccine, oral rabies vaccine) and bacterial (i.e., oral cholera vaccine, oral E. coli vaccine, Staphylococcus aureus intramammary vaccine) pathogens (Levine et al., 2000; Pavot et al., 2012; Vilte et al., 2012; Gogoi-Tiwari et al., 2015). Hogan et al. (1997) and Smith et al. (1999) studied the effect of a systemic vaccination in combination with an intramammary $E$. coli J5 bacterin immunization schedule on responses of antibody titers. The results showed that intramammary immunization enhanced IgG titers in serum in the dry period and in lactation and in whey in early lactation compared with subcutaneous immunizations (Hogan et al., 1997; Smith et al., 1999). However, the immunization schedule had minimal effect on systemic and local signs of clinical mastitis following challenge. Smith et al. (1999) concluded that the reason for this lack of protection was due to the 4-h boiling of the bacteria in the creation of the bacterin vaccine.

More recent studies have used so-called ghost bacteria as vaccine organisms. These ghost organisms are killed bacteria where the internal structures of the bacteria are destroyed but the bacterin have the same cell surface composition as their living counterparts (Mayr et al., 2005). Such ghost organisms display all surface components in a natural nondenatured form, even highly sensitive and fragile structures such as pili are well protected. It has been shown that ghost organisms are able to induce a strong mucosal immune response (Jalava et al., 2003). The potency, safety, and relatively low production cost of bacterial ghosts also offer a significant technical advantage (Yuki and Kiyono, 2003; Mayr et al., 2005; Lubitz et al., 2009).

Therefore, the objective of the current study was to evaluate the efficacy of intramammary immunization with UV-killed E. coli ECC-Z on prevention of intramammary colonization after a challenge with a dose of the homologous E. coli ECC-Z bacterium prepartum, a period of heightened susceptibility to IMI. The $E$. coli ECC-Z strain used for our study has been used in previous challenge trials in both the dry period and lactation, is well characterized, and known to cause mild clinical mastitis (Dogan et al., 2006; Quesnell et al., 2012; Sipka et al., 2013; Lippolis et al., 2014). The effect of immunization on clinical signs, milk production, SCC, and cytokine profiles was also evaluated.

\section{MATERIALS AND METHODS}

\section{Cows}

Ten adult Holstein cows were selected from the Cornell University Teaching and Research Dairy herd. Selection was based on the following criteria: cows had completed at least 1 previous lactation and were expected to have an approximate 45 - to 48 -d dry period. Also, cows with any signs of detectable illness, including but not limited to clinical mastitis at time of dry off or with any of the last 6 monthly individual cow SCC before dry off greater than 250,000 cells/mL, were excluded. Cows were culture-negative at time of enrollment, and culture-negative before challenge with E. coli ECC-Z as determined by bacteriology described within the section Mammary Gland Secretion and Blood Sample Collection. Finally, cows with any major traumatic injury to the teat ends were excluded.

\section{Housing}

Cows in both groups were housed, fed, and managed identically throughout the dry period and postpartum. Three weeks before the anticipated calving date, cows were transferred from freestalls to the Cornell University Large Animal Research and Training Unit facility. Here the cows were housed in individual maternity pens and had unlimited access to water and feed. Cows remained in the study throughout the nonlactating period, calving, and first $7 \mathrm{~d}$ of the ensuing lactation. No adverse reactions to the vaccine before the intramammary E. coli challenge were observed in any of the cows. The study protocol was approved by the Cornell University committee on Animal Use and Care (protocol 2006-0158).

\section{Parenteral Vaccination and Intramammary Immunization}

The selected cows were paired by expected calving date so they were approximately the same and then were randomized to receive parenteral J5 vaccine or serve as control. The J5 vaccine (Escherichia coli Bacterin, J5 strain; Zoetis, Kalamazoo, MI) was administered by 
the investigators $(5 \mathrm{~mL})$ subcutaneously on the upper part of the rib cage just posterior to the scapula. The cows in the control group were unvaccinated controls. Vaccinated cows were immunized $15 \mathrm{~d}$ before dry off followed by a second dose at dry off and a third dose 15 d after dry off. Cows in both the groups were dried off by abrupt cessation of milking and all 4 quarters were left untreated with no internal teat sealant.

In addition to the systemic vaccination, all cows received an intramammary immunization of the equivalent approximately $100 \mathrm{cfu}$ of UV-irradiated $E$. coli ECC-Z at the time of dry-off in 1 of the 2 hind quarters. The production of the UV-killed E. coli is described here in brief. The E. coli ECC-Z bacterial strain was grown in Luria Bertani (LB) broth until a concentration of approximately $10^{6}$ bacteria per milliliter of broth was obtained. Approximately $1 \mathrm{~L}$ of broth was then irradiated. The UV irradiation device was composed of a stainless steel outer unit containing 3 inner chambers of quartz tubes connected in sequence. The bacterial broth was pumped through a thin layer between the outer steel unit and inner quartz tubes. Eight germicidal low-pressure mercury lamps were used as the source of UV light exposure. Every $50 \mathrm{~ms}, 2$ UVX-25 UV light sensors (UVP LLC, Upland, CA) monitored the desirable amount of UV energy required for consistent radiation. The resulting UV-radiated bacterial solution was checked for bacterial growth. No live bacteria were recovered. The sterility of the UV-irradiated broth was checked before each intramammary application. Throughout this manuscript, the intramammary application of these ghost bacteria will be referred to as immunization rather than vaccination.

\section{Intramammary Bacterial Challenge}

Escherichia coli strain ECC-Z (Dogan et al., 2006), a strain originally isolated from a cow with mild, persistent clinical mastitis (Lippolis et al., 2014), was used as the intramammary challenge strain. The challenge inoculum was prepared by inoculating a frozen stock culture of the ECC-Z strain into LB broth. The LB broth was incubated for $18 \mathrm{~h}$ at $37^{\circ} \mathrm{C}$. A total of 100 $\mu \mathrm{L}$ of this culture was inoculated into fresh LB broth and incubated for approximately $2.5 \mathrm{~h}$ at $37^{\circ} \mathrm{C}$. The log phase LB broth culture was used for inoculation. A 1:10 dilution of the log phase culture was made in PBS and adjusted to $100 \mathrm{cfu}$ of inoculation dose. The colonyforming units per milliliter of the challenge bacteria was determined by plating $100 \mu \mathrm{L}$ in duplicate on LB agar plates. Two hind quarters of each control or parenterally vaccinated cow was challenged by infusion of approximately $100 \mathrm{cfu}$ of $E$. coli $\mathrm{ECC}-\mathrm{Z}$ strain suspended in PBS. The cows were challenged approximately $10 \mathrm{~d}$ before the expected calving date, a third quarter received a similar infusion of vehicle (PBS) only, whereas the fourth quarter remained unchallenged.

\section{Mammary Gland Secretion and Blood Sample Collection}

Milk or dry cow secretion samples were collected at the time of vaccinations, at the time of intramammary immunization and daily thereafter for $7 \mathrm{~d}$, from $1 \mathrm{wk}$ before to the day of challenge on a daily basis, at the time of challenge and every $12 \mathrm{~h}$ thereafter until 72 $\mathrm{h}$ after challenge, and from the day of calving until 7 $\mathrm{d}$ thereafter at every milking ( $12 \mathrm{~h}$ apart). Previous work demonstrates that frequency of sampling in the dry period, when using an aseptic technique as done here, is not associated with clinical mastitis (Green et al., 2002).

Milk and dry cow secretions (hereafter referred to as dry cow mammary gland secretions, DCS) were aseptically collected in sterile vials for microbiological culture and cytokine analysis. All 4 quarters were sampled individually. For cytokine analyses, milk samples were centrifuged at $20,000 \times g$ and $4^{\circ} \mathrm{C}$ for $30 \mathrm{~min}$. The fat layer was removed and milk whey was collected and stored in aliquots at $-20^{\circ} \mathrm{C}$ until ELISA analyses. For microbiological culture, samples were transported immediately on ice to the microbiology laboratory for culture according to the protocols recommended by the National Mastitis Council and described in detail by Hogan et al. (1992). Briefly, $100 \mu \mathrm{L}$ of milk or DCS was plated on Columbia Sheep Blood agar (Oxoid, Basingstoke, UK) and MacConkey's agar plate (Becton, Dickinson and Company, Franklin Lakes, NJ). Plates were incubated for 24 to $48 \mathrm{~h}$ at $37^{\circ} \mathrm{C}$ and were examined daily for bacterial growth. As previously described in Gurjar et al. (2013), representative individual colonies were isolated and stored at $-70^{\circ} \mathrm{C}$ for molecular strain typing by random amplification of polymorphic DNA (RAPD) analysis to identify challenge strain E. coli ECC-Z. In brief, individual isolates from bacterial culture plates were grown in LB broth at $37^{\circ} \mathrm{C}$ for $12 \mathrm{~h}$. The DNA was isolated from samples using a QIAquick DNeasy isolation kit (Qiagen Inc., Valencia, CA). The RAPD primers designed specifically for RAPD typing of gram-negative bacteria were as follows: forward 5'-AGTAAGTGACTGGGGTGAGCG-3' and reverse 5'-TACATTCGAGGACCCCTAAGTG-3'. These primers have previously been shown to provide discernment between mastitis E. coli bacterial strains (Dogan et al., 2006). The PCR products were evaluated using gel electrophoresis in a 1.5\% agarose gel at $60 \mathrm{~V}$ for $1.5 \mathrm{~h}$. 
Bacteria counts were obtained through 3 serial 10-fold dilutions. Where necessary, additional dilutions were performed for peak colony-forming units counts, which occurred roughly around challenge $+18 \mathrm{~h}$. The results of the bacteriological analysis were expressed as $\log _{10}$ colony-forming units per milliliter of milk. An aliquot of each milk sample was sent to Dairy One (Ithaca, NY) for SCC determination using a Fossomatic cell count analyzer (Foss, Hillerød, Denmark). Data were counted as SCC per milliliter of milk and expressed as a linear score. In the post calving period, the animals were milked with a quarter-milker and 4 Lactocorders (WMB, Balgach, Switzerland), each connected to a single quarter. This enabled determining the milk production and conductivity from individual quarters with the aid of the Lactocorder device.

\section{Clinical Observation for Local and Systemic Signs}

Systemic and local symptoms of inflammation were assessed throughout the trial period as described by Petzl et al. (2012). All time periods indicated above for collection of blood and milk or DCS samples were also used for recording clinical signs. Rectal temperature, appetite, and general attitude were evaluated. The systemic signs were scored on a 3 -point scale, where 1 $=$ no signs and $3=$ severe systemic signs. The udder was palpated for soreness, swelling, and hardness. The udder was scored on a 1 to 4 scale, with 1 being normal and 4 being the gland swollen, warm, sore, firm, and with a red discoloration. The milk appearance, consistency, and color were scored daily in the postcalving period at every 12 -h interval. The milk appearance was scored on a 4-point scale, with 1 being normal white homogenous milk and 4 being dark yellowish milk with clots as observed on the Lactocorder filter. The 3 scores, cow, udder, and milk score, were then added to an overall clinical score. Cows with overall clinical score of 3 or less were recorded as having no clinical mastitis, those with scores between 4 and 7 as having mild to moderate mastitis, and those with scores of $\geq 8$ as having severe mastitis.

\section{Cytokine Analysis}

Sample plates with 96 wells (Thermo-Fisher, Pittsburg, PA) were coated with a primary capture antibody for IFN- $\gamma(1 \mu \mathrm{g} / \mathrm{mL}$, CLONE, Serotec Inc., Raleigh, NC) and IL-10 (5 $\mu \mathrm{g} / \mathrm{mL}$, CLONE, Serotec Inc.) in a $0.05 M$ carbonate coating buffer, $\mathrm{pH}$ 9.6. Plates were allowed to incubate overnight at $4^{\circ} \mathrm{C}$. All plates, washes, and blocking reagents were allowed to equilibrate to room temperature. Plates were washed 3 times with wash buffer (50 $\mathrm{m} M$ Tris-buffered saline with $0.05 \%$ tween-20, pH 8.0) and blocked with 1:10 Seablock:Trisbuffered saline (Pierce, Rockford, IL) for $1 \mathrm{~h}$. Subsequently, plates were washed again 3 times with wash buffer. Recombinant proteins for cytokine IFN- $\gamma$ were diluted to appropriate concentrations and included as a standard curve for each assay. Due to unavailability of recombinant bovine IL-10 at the time this study was conducted, we could not run standards for IL-10 with this assay; IL-10 was therefore expressed as measured optical density (OD) values. For each assay 100 $\mu \mathrm{L}$ of standards and samples were incubated at room temperature for at $2 \mathrm{~h}$. Plates were washed 3 times with wash buffer. Biotin-labeled secondary antibodies: IFN- $\gamma(5 \mu \mathrm{g} / \mathrm{mL}$, CLONE, Serotec Inc.) and IL-10 (5 $\mu \mathrm{g} / \mathrm{mL}$, CLONE, Serotec Inc.) diluted in blocking buffer were added to the wells $(100 \mu \mathrm{L} /$ well $)$. Plates were incubated for $1 \mathrm{~h}$ at room temperature in the dark. Plates were washed 3 times in wash buffer, and following washing steps streptavidin:horseradish peroxide complex diluted 1:1,000 in blocking buffer was added to wells $(100 \mu \mathrm{L} /$ well $)$ and incubated in the dark for $1 \mathrm{~h}$ at room temperature. Plates were washed 3 times in wash buffer and $100 \mu \mathrm{L} /$ well of $3,3^{\prime}, 5,5^{\prime}$-tetramethylbenzidine was added to each well. Plates were incubated for 10 to $25 \mathrm{~min}$ at room temperature in the dark and $100 \mu \mathrm{L} /$ well of $2 \mathrm{M} \mathrm{H}_{2} \mathrm{SO}_{4}$ was added to wells. The concentrations of IFN- $\gamma$ in the whey samples were calculated by extrapolating from the respective standard curves, and the values expressed as biological units of activity per milliliter. A background correction reading at $565 \mathrm{~nm}$ was subtracted from the $450-\mathrm{nm}$ absorbance readings.

\section{Data Analysis}

Data were entered into spreadsheets and checked for entry errors. All data were analyzed using SAS ver. 9.4 statistical analysis program (SAS Institute Inc., Cary, NC). Initially data were graphed and evaluated for outliers and unlikely observations. Outliers were studied in detail and reanalyzed to confirm where necessary. Differences in linear score of SCC, milk production, conductivity, clinical score, and $\log _{10}$ (bacteria count) were analyzed using linear mixed models (SAS, PROC MIXED), adjusting for repeated measures within animals and using Bonferroni for post hoc tests. The general format of the model was:

$$
\begin{aligned}
\mathrm{Y}= & \alpha+\beta_{1} \times \text { time point }+\beta_{2} \times \text { immunization } \\
+ & \beta_{3} \times \text { vaccination }+\beta_{4} \times \text { immunization } \\
& \times \text { vaccination }+ \text { Cow }(\text { random })+\text { Re }
\end{aligned}
$$


where $\mathrm{Y}$ is the outcome variable, $\alpha$ is the intercept, $\beta_{\mathrm{i}}$ are regression coefficients, time point is a categorical variable for each time point of measurement, immunization is a dummy variable $(1=$ yes, $0=$ no $)$, vaccination is a dummy variable $(1=$ yes, $0=$ no), immunization $\times$ vaccination is the interaction term, Cow is a random cow effect, and Re is a complex error term, where $\mathrm{R}$ is the within cow correlation and e is an identically, independently normally distributed error term. A very similar model was used for the IMI outcome variable, but this was analyzed in a logistic regression term where logit(probability of IMI) was the outcome variable. A somewhat more complex model was used for cytokine profile analysis. The model used for analysis was

$$
\begin{aligned}
& \mathrm{Y}=\alpha+\beta_{1} \times \text { time point }+\beta_{2} \times \text { immunization } \\
& +\beta_{3} \times \text { vaccination }+\beta_{4} \times \text { immunization } \\
& \times \text { vaccination }+\beta_{5} \times \text { prechallenge average }+\beta_{6} \\
& \quad \times \text { postchallenge }+\beta_{7} \times \text { immunization } \\
& \quad \times \text { postchallenge }+ \text { Cow }(\text { random })+\text { Re },
\end{aligned}
$$

where all terms are the same as previous, prechallenge average is the average cytokine level of the 3 samples taken immediately before challenge $(-7,-4$, and $0 \mathrm{~d})$, postchallenge is an indicator variable taking on the value of 1 for the time points $12 \mathrm{~h}$ to $7 \mathrm{~d}$ and all time points in between and the final interaction reflects the effect of immunization on the cytokine profile in the time periods immediately after challenge. Differences were considered statistically significant when the probability of a type I error is $<0.05$.

\section{RESULTS}

\section{Clinical Data}

No major clinical disease issues were encountered with the 10 cows that were enrolled into the trial. All cows went through the trial, eventually recovered from challenge infection, and were all returned to the teaching and research dairy facility. Clinical scoring of cows and milk of the cows was done at every milking. After challenge with E. coli ECC-Z, clinical abnormalities were observed in almost all cows, but none of the cows became systemically sick due to clinical mastitis. The result of the regression analysis (results not shown) of the clinical score indicated that the quarters that were immunized had a lower score by an average of 0.09 score points, and this reduction was borderline significant with a $P$-value of 0.07 . All challenged quarters, immunized and nonimmunized, showed a significantly increased score that had increased with an average of 0.15 compared with nonchallenged control quarters $(P<0.01)$. The least squares means obtained from the regression model are shown in Figure 1. The clinical score in the challenged but nonimmunized control quarters started out higher immediately after calving and then became approximately identical to the immunized quarters after $3 \mathrm{~d}$. Body temperature of the

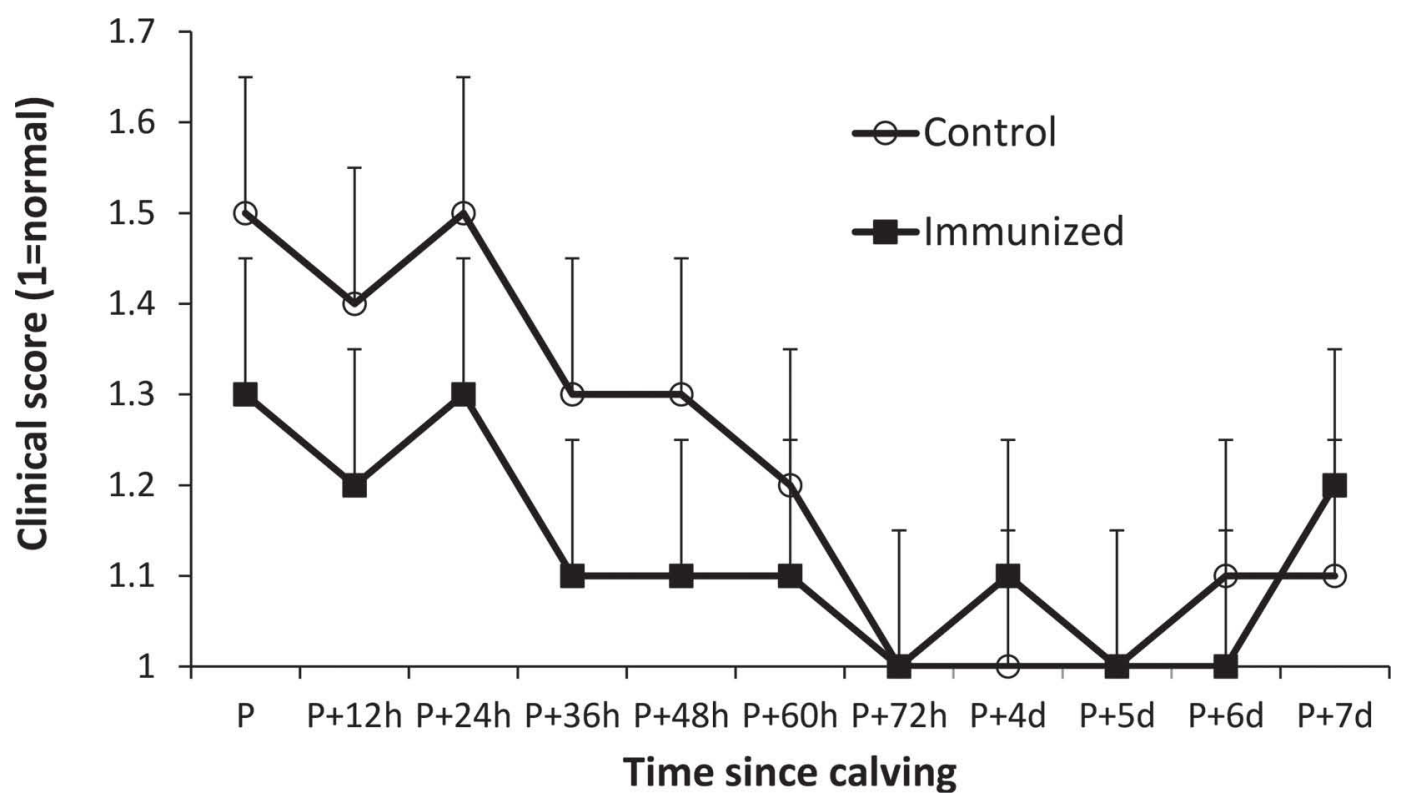

Figure 1. Least squares means of the clinical score in unimmunized control quarters and quarters that were immunized. Time points refer to time relative to parturition (P). Error bars represent the SE of the LSM estimates. 
cows throughout the trial was on average $38.6^{\circ} \mathrm{C}$ (SD 0.52 ), with no significant differences observed between the vaccinated and control cows, at 38.6 (SD 0.57) and $38.5^{\circ} \mathrm{C}$ (SD 0.45), respectively.

\section{IMI}

The effect of immunization on bacteria counts is shown in Table 1. Intramammary infection was defined as a sample being culture-positive for E. coli ECC-Z as determined by RAPD of isolates. In Table 1, the $\log _{10}$ bacteria counts were used as the outcome variable for linear mixed model regression. Of the challenged, unimmunized control quarters, 10 out of 10 quarters were at least once positive for E. coli ECC-Z; 1 out of these 10 quarters was only positive at the very first postchallenge sampling. Of the challenged, immunized quarters, 7 out of 10 quarters were at least once positive; 5 out of these 7 quarters were only positive at the very first postchallenge sampling. The results indicate that the $\log _{10}$ bacteria counts are significantly lower in the immunized quarters relative to the control quarters. The average drop in bacteria count was 0.33 log units and this was highly significant $(P<0.0001)$. Parenteral vaccination did not contribute to a further reduction in bacteria counts once the effect of intramammary immunization was accounted for $(P=0.13)$. The least squares means of the linear mixed model regression are shown in Figure 2a. A very clear distinction between immunized and control quarters is evident. We also noted a clear bimodality in the graphs, where bacteria counts are dropping at $5 \mathrm{~d}$ after challenge before calving, but then increase again as soon as the cow has calved. The logistic mixed model regression results on the probability of a new IMI is also shown in Table 1. Again, immunized quarters had a significantly lower probability of being infected. The odds ratio of being infected can be estimated as $0.2\left(=\mathrm{e}^{-1.63}\right)$, or control quarters are 5 times more likely of being infected compared with immunized quarters. In Figure $2 \mathrm{~b}$, the probability of a quarter being culture-positive is calculated and plotted over time. Immunized quarters had a higher probability of becoming culture-negative immediately after challenge $(P<0.05)$. The immunized quarters also had a lower probability of being infected postcalving.

\section{Milk Production, SCC, and Conductivity}

Quarter milk production was measured using the Lactocorder device. Milk production regression results indicated that the immunized quarters had an increased quarter milk production of $0.58 \mathrm{~kg} /$ milk per day $(P<0.01)$. Parenteral vaccination did not have a significant effect on milk production once immunization was accounted for $(P=0.40)$. The least squares means resulting from the final regression model are shown in Figure 3. Milk production started out approximately equal between the unimmunized, challenged control quarters and immunized, challenged quarters, but, in the days after calving, milk production in immunized quarters increased relative to unimmunized quarters for the duration of the trial. In Table 2, the linear mixed model regression of the linear score of the SCC at quarter level are shown. Immunized quarters had a significantly lower linear score by 0.40 linear score units; challenge increased the linear score. The least squares means of this model are shown in Figure 4a. Table 2 shows the linear mixed model regression results of milk conductivity. The average conductivity in immunized, challenged quarters was significantly lower compared with unimmunized, challenged quarters. Least squares means from the regression model on milk conductivity are shown in Figure 4b.

\section{Cytokine Profiles}

Cytokine profiles for IFN- $\gamma$ and IL-10 are shown in Figure $5 \mathrm{a}$ and $5 \mathrm{~b}$, respectively. For both cytokines the concentrations in milk were already higher immediately before the challenge relative to the levels at the time of the vaccinations and the intramammary immunization. For that reason, a covariate was added into the linear model that corrected for the mean level of the cytokine immediately before challenge (prechallenge

Table 1. Effect of immunization on bacterial counts and probability of IMI in the challenged quarters ${ }^{1}$

\begin{tabular}{lcccccccc}
\hline & \multicolumn{3}{c}{ Bacterial count } & & \multicolumn{3}{c}{ Probability of IMI } \\
\cline { 3 - 4 } \cline { 7 - 9 } Effect & Estimate & $\mathrm{SE}$ & $\mathrm{Pr}>|\mathrm{t}|$ & & Estimate & $\mathrm{SE}$ & $\operatorname{Pr}>|\mathrm{Z}|$ \\
\hline Intercept & & -0.30 & 0.26 & 0.28 & & -2.36 & 0.47 & $<0.001$ \\
Time point & & $\mathrm{NA}$ & $\mathrm{NA}$ & 0.00 & & 3.06 & 0.99 & 0.00 \\
Vaccine & Yes & 0.41 & 0.27 & 0.13 & & 0.99 & 0.73 & 0.17 \\
Immunization & Yes & -0.33 & 0.08 & $<0.001$ & & -1.63 & 0.60 & 0.01 \\
\hline
\end{tabular}

${ }^{1}$ Bacterial counts were $\log 10$-transformed and analyzed in a linear model, probability of IMI was binary and analyzed used a logistic regression model. The t- and Z-critical values to determine if coefficients are significantly different from 0 are based on a 2-tailed test with an alpha of 0.05 . 
average was the average of $\mathrm{d}-7,-4$, and 0$)$. Results of the linear models are shown in Table 3. The key variable to evaluate in this table is the interaction between immunization and postchallenge. In the case of IFN- $\gamma$, this interaction has a parameter value of 1.68 , indicating that immediately after challenge the IFN- $\gamma$ level in immunized quarters increased by 1.68 units compared with the control quarters. In the case of IL-10, the opposite was shown. In immunized quarters, IL-10 levels dropped by 0.74 units in immunized quarters immediately after challenge compared with control quarters.

These 2 effects are shown in detail in Figure 5 . Interferon- $\gamma$ levels increased significantly postchallenge, but only in the immunized quarters; nonimmunized quarters showed no increase due to challenge (Figure $5 a)$. This increase in IFN- $\gamma$ levels after challenge was of relative short duration and the levels were back to the level of nonimmunized quarters at approximately 4
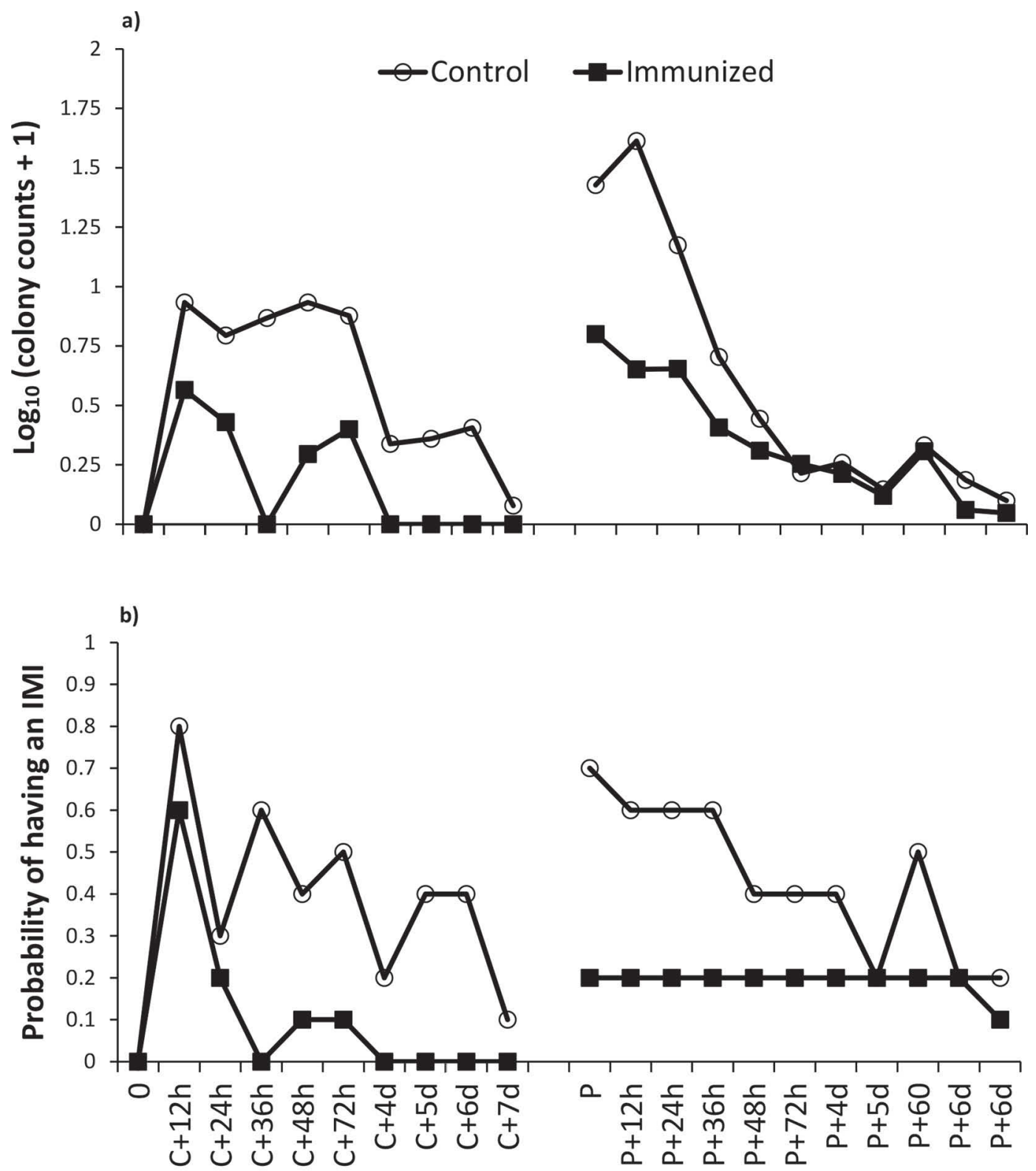

Time relative to challenge or parturition

Figure 2. (a) Least squares means of mixed model regression on $\log _{10}$ bacteria counts and (b) probability of having an IMI in the immunized and unimmunized control quarters. Time points refer to time relative to challenge $(\mathrm{C})$ or parturition $(\mathrm{P})$. 


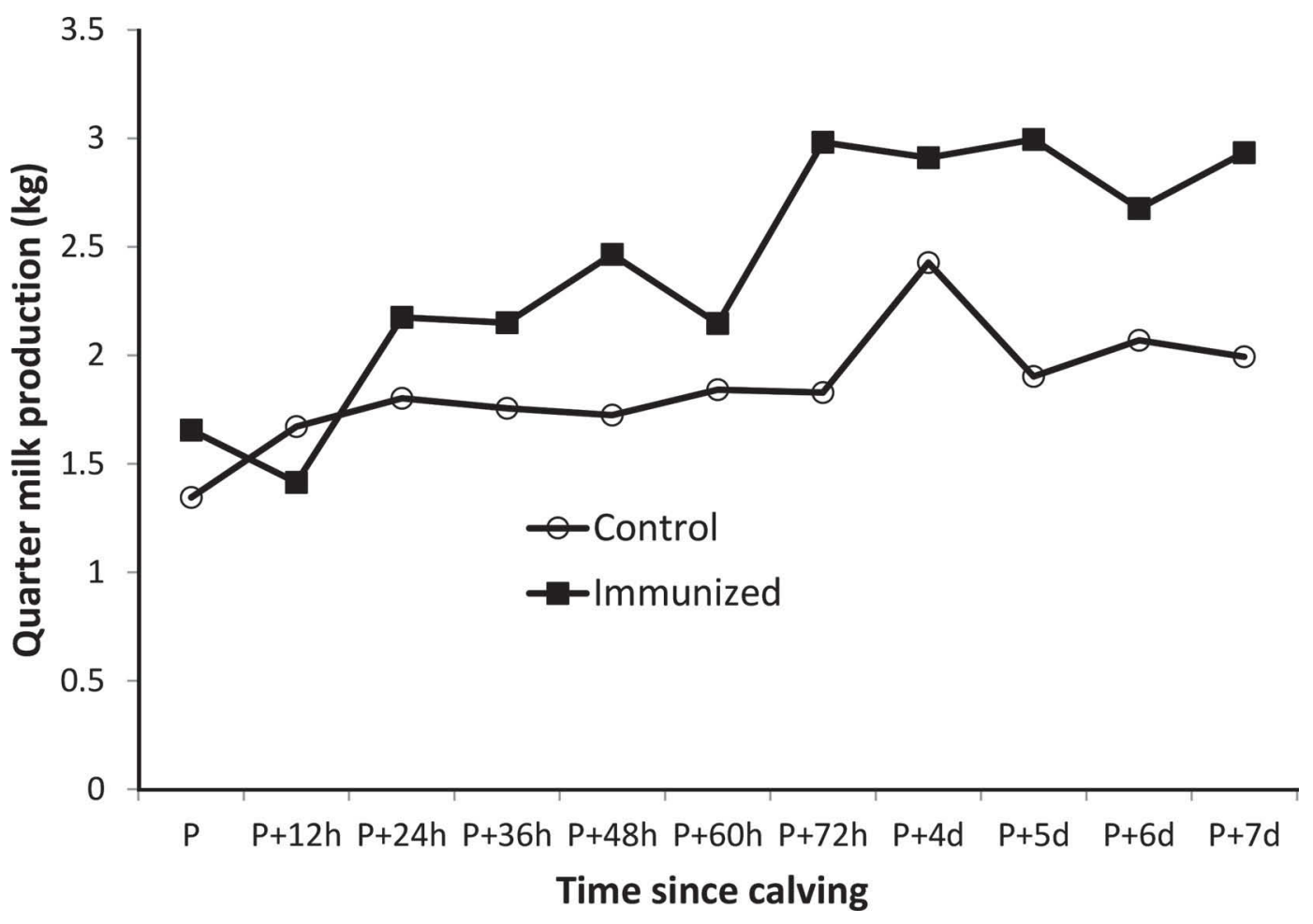

Figure 3. Least squares means of quarter milk production in immunized and unimmunized control quarters. Time points refer to time relative to parturition $(\mathrm{P})$.

d postchallenge. After calving, IFN- $\gamma$ levels decreased again and went back to the levels of the period before dry off and during vaccination. Figure $5 \mathrm{~b}$ shows the levels of IL-10 in immunized and control quarters. A slight, but in this case nonsignificant, increase in IL-10 was noted immediately before challenge. The level of IL-10 was significantly lower after challenge in quarters that were immunized compared with the control quarters. Immediately after calving IL-10 levels in immunized quarters spiked and then returned to prechallenge levels. After calving, no difference in IL-10 levels were observed between immunized and control quarters.

\section{DISCUSSION}

The results of the intramammary immunization study in 10 cows showed a partially protective effect of intramammary immunization at dry off on the outcome of a subsequent intramammary challenge in the late dry period. Immunization resulted in a 5 -fold lower probability of infection (odds ratio of 0.2 ), and a lower bacterial load. These results provide the first strong evidence that intramammary immunization with UV-killed $E$. coli bacterin in dairy cows may improve the outcome of an intramammary infections acquired in the dry period.

Table 2. Linear mixed model results of linear score and electrical conductivity in immunized and control quarters; both models used were linear regression models ${ }^{1}$

\begin{tabular}{|c|c|c|c|c|c|c|}
\hline \multirow[b]{2}{*}{ Effect } & \multicolumn{3}{|c|}{ Linear score } & \multicolumn{3}{|c|}{ Conductivity } \\
\hline & Estimate & $\mathrm{SE}$ & $\operatorname{Pr}>|t|$ & Estimate & SE & $\operatorname{Pr}>|t|$ \\
\hline Intercept & 2.45 & 0.23 & $<0.001$ & 4.34 & 0.27 & $<0.001$ \\
\hline Time point & NA & NA & $<0.001$ & NA & NA & $<0.001$ \\
\hline Challenge & 0.18 & 0.07 & 0.01 & 0.92 & 0.10 & $<0.001$ \\
\hline Vaccine & 0.40 & 0.29 & 0.17 & 0.23 & 0.31 & 0.46 \\
\hline Immunization & -0.40 & 0.08 & $<0.001$ & -1.43 & 0.12 & $<0.001$ \\
\hline
\end{tabular}

${ }^{1}$ The $t$ - and Z-critical values to determine if coefficients are significantly different from 0 are based on a 2-tailed test with an alpha of 0.05 . 
The results of intramammary immunization appear to be more protective compared with systemic vaccination, which most often does not reduce the IMI risk (Hogan et al., 1992; Wilson et al., 2008). The precise mechanism that would lead to this protection against infection is not known, but it may be hypothesized that immunization with UV-killed $E$. coli is protective. This is in line with a series of studies on protective effects of mucosal immunization with oral administration of $E$. coli ghost bacteria in defense against experimental infection in mice (Mayr et al., 2005, 2012). In a recent study on intramammary immunization of mice against a subsequent Staph. aureus challenge, it was also shown that intramammary immunization significantly reduced bacterial load after challenge when compared with subcutaneous vaccination or a nontreated control group (Gogoi-Tiwari et al., 2015, 2016). Gogoi-Tiwari et al.
(2015) also suggested that the enhanced generation of antigen-specific humoral and cell-mediated immunity observed following intramammary immunization lead the superior protection against Staph. aureus challenge.

The second important finding was that intramammary immunization resulted in lower SCC and milk conductivity, a somewhat lower clinical mastitis score, and increased milk production compared with challenged, unimmunized quarters. Part of this effect may be attributed to the much lower risk of infection and lower bacteria counts in quarters that did get infected; however, even in infected quarters, the severity of signs was numerically, but not statistically, lower in immunized quarters (data not shown). Reduction in clinical severity caused by IMI present in early lactation by UV-killed bacterin intramammary immunization in at dry off needs further investigation to differentiate
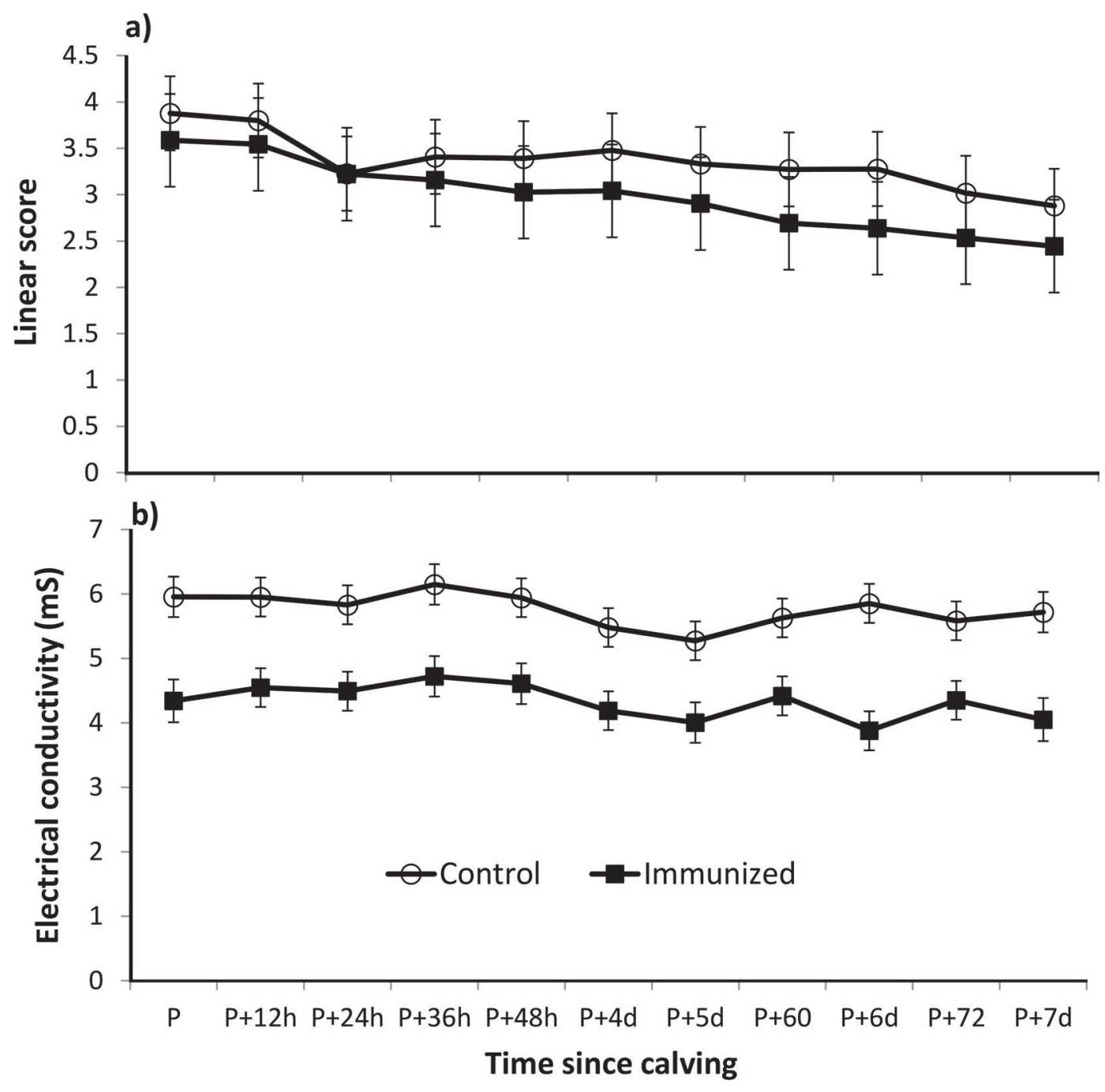

Figure 4. Least squares means of (a) linear score and (b) electrical conductivity in immunized and unimmunized control quarters. Time points refer to time relative to parturition $(\mathrm{P})$. Error bars represent the SE of the LSM estimates. 

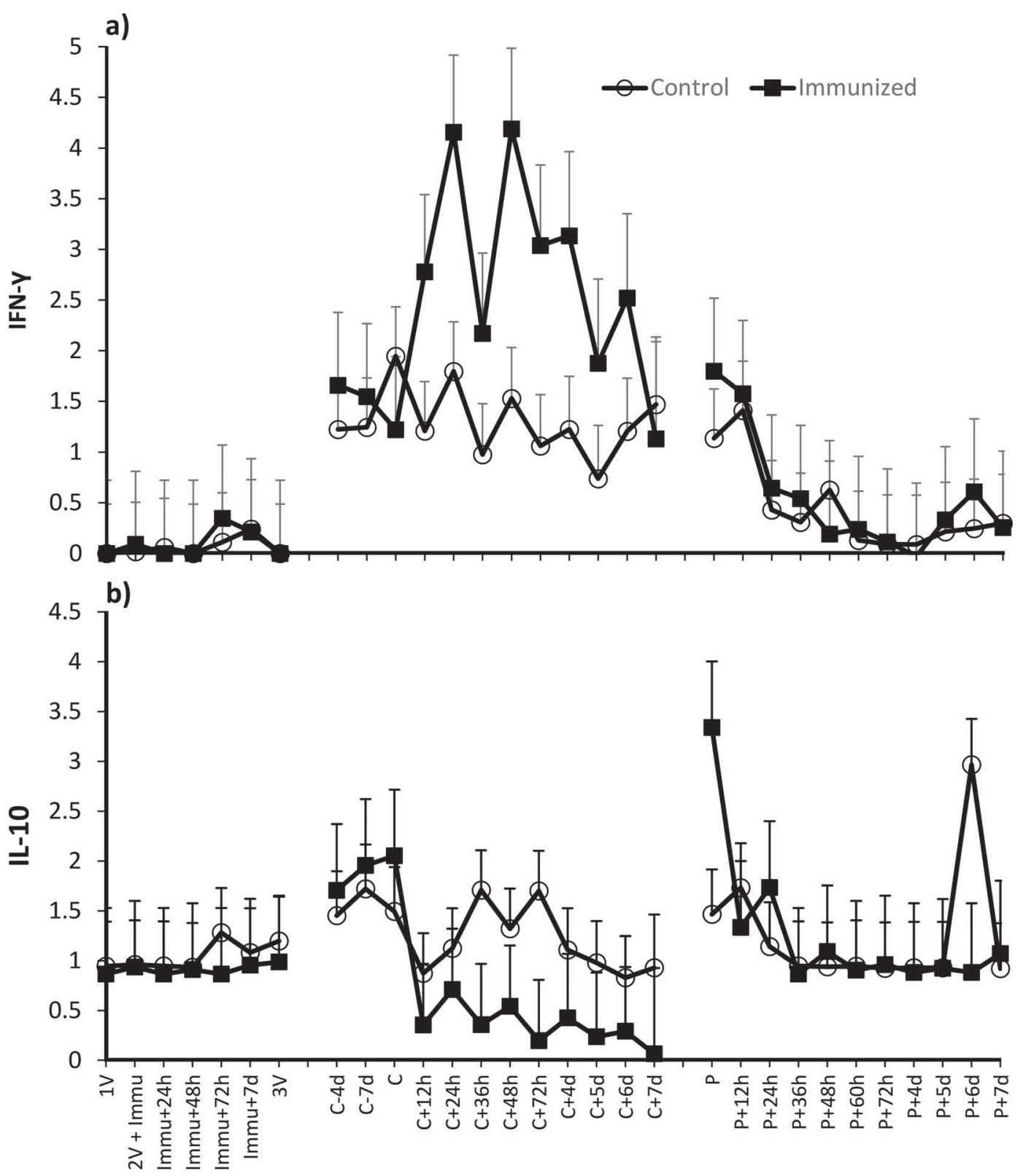

Figure 5. Least squares means of (a) IFN- $\gamma$ cytokine values and (b) IL-10 in unimmunized control and immunized quarters. Time points refer to time relative to challenge $(\mathrm{C})$ or parturition $(\mathrm{P})$. Time of peripheral vaccination $(\mathrm{V})$ is indicated. Error bars represent the SE of the LSM estimates.

between cases in which there was full protection versus partial protection.

Another valuable finding in our study was the difference in cytokine profile observed between immunized and challenged versus unimmunized and challenged quarters. The unimmunized control quarters responded as shown by Quesnell et al. (2012), with no significant increase in proinflammatory cytokine production following challenge, in this case IFN- $\gamma$, and increased concentration of IL-10 after challenge relative to immu- nized, challenged quarters. In contrast, the immunized quarters showed a modified proinflammatory response, with a moderate increase in IFN- $\gamma$ and a decrease in IL-10 concentrations following challenge. Our study indicates the suggested maternal immune regulation of proinflammatory, Th1-type responses described in late gestation may be modified in the mammary gland with intramammary immunization (Rosbottom et al., 2008; Quesnell et al., 2012; Maeda et al., 2013; Paibomesai et al., 2013; Schumacher et al., 2014; Pomeroy et al., 
Table 3. Linear mixed model for IFN- $\gamma$ and IL-10; both models used were linear mixed models ${ }^{1}$

\begin{tabular}{|c|c|c|c|c|c|c|}
\hline \multirow[b]{2}{*}{ Effect } & \multicolumn{3}{|c|}{ IFN- $\gamma$} & \multicolumn{3}{|c|}{ IL-10 } \\
\hline & Estimate & $\mathrm{SE}$ & $\operatorname{Pr}>|t|$ & Estimate & $\mathrm{SE}$ & $\operatorname{Pr}>|t|$ \\
\hline Intercept & -0.57 & 0.53 & 0.31 & 0.03 & 0.36 & 0.95 \\
\hline Time point & NA & NA & 0.90 & NA & NA & 0.006 \\
\hline Immunization & 0.06 & 0.17 & 0.70 & -0.09 & 0.17 & 0.59 \\
\hline Vaccine & -0.66 & 0.67 & 0.33 & 0.29 & 0.20 & 0.15 \\
\hline Prechallenge average & 0.57 & 0.10 & $<0.001$ & 0.15 & 0.09 & 0.14 \\
\hline Postchallenge & 2.51 & 0.29 & $<0.001$ & 0.01 & 0.28 & 0.98 \\
\hline Immunization $\times$ postchallenge & 1.68 & 0.39 & $<0.001$ & -0.74 & 0.32 & 0.02 \\
\hline
\end{tabular}

2015). This may suggest that mucosal immunity in the mammary gland is more flexible during this period of maternal immune regulation. Previous studies on mucosal immunization against E. coli using ghost bacteria have shown, in addition to improved humoral immunity, an enhanced antigen-specific IFN- $\gamma$ response following challenge with the target antigen (Mayr et al., 2005, 2012). Additionally, nonspecific priming of innate immune cell populations at mucosal sites, such as monocytes and macrophages, which induce epigenetic changes to generate what is known as trained immunity, has been well-documented in other species and these effects have been shown to improve the efficacy of immunization and the protection against secondary, nontarget infections (Benn et al., 2013; Blok et al., 2015). Since antigen-specific immunity was not determined by either antibody titers or in vitro recall responses, it cannot be determined from our study which cell types were affected by the immunization and whether the enhanced protection from $E$. coli IMI was due to the generation of primed tissue-resident innate immune cells or antigen-specific lymphocytes by intramammary immunization. The mechanisms involved can only be speculated at this point based on current understanding in immunomodulation and immune programming.

The mechanism of action of such a local immunization of the mucosa in the mammary gland is not fully understood. Although few studies have been published on intramammary immunization, Colditz and Watson (1985) reported on intramammary immunization of sheep to prevent IMI with Staph. aureus bacteria. Glands locally immunized with killed Brucella abortus provided a greater neutrophil response to staphylococcal infection. Secretions of these immunized glands contained elevated concentrations of mononuclear cells. Colditz and Watson (1985) concluded that humoral and cellular characteristics of the locally immunized mammary gland influences the kinetics of the neutrophil influx during staphylococcal infection. The studies on intramammary immunization in dairy cows by Smith et al. (1999) did not show any protective effect of the immunization (i.e., no difference in clinical signs, bacterial load, or cell influx observed between immunized and control quarters), despite the enhanced antibody response in the mammary secretum. Smith et al. (1999) hypothesized that the extensive boiling of the organisms before use as a vaccine may have resulted in low antigenic properties of this solution. It has been suggested that ghost bacteria alone are able to stimulate both the innate and adaptive immune system (Lubitz et al., 2009). The use of ghost bacteria may have been a key difference between the earlier studies of Smith et al. (1999) and the current studies using intramammary application of ghost bacteria, such as UV-killed bacterin.

Although our results are preliminary and obtained on only 10 cows, they certainly appear to provide insight into the biological benefits of triggering mucosal immunity in the mammary gland. The current study used 10 adult cows and showed a significant effect on bacterial infection risk after challenge. Still, this first study with 10 cows will need to be repeated to be able to provide more solid evidence that intramammary immunization with UV-killed bacterin is indeed efficacious in reducing IMI. The use of a homologous challenge provides the best possible scenario to show efficacious protection of intramammary immunization. Obviously, such homologous challenge is not a very realistic scenario for commercial dairy farms. Further experimental work with heterologous organisms will be necessary to show a broad spectrum of efficacy (Schukken et al., 2011). Ultimately, such intramammary immunization with UV-killed bacterin will need to be effective under field conditions. Not only is it essential to show further efficacy in repeated studies with heterologous challenge, it is also necessary to obtain a better mechanistic understanding of the immune response that is stimulated using this novel vaccination approach (Bharathan and Mullarky, 2011). Finally, it will be essential to develop an application system that under all management circumstances will be both effective and safe. Appli- 
cation of UV-killed bacterin into the mammary gland certainly also provides a risk for contamination at the time of heightened susceptibility to infection. Therefore, further investigations into the mechanisms and clinical efficacy of intramammary immunization are warranted based on the promising observations in the study reported here.

\section{CONCLUSIONS}

Intramammary immunization at the time of dry-off with UV killed E. coli bacterin without addition of adjuvant proved to be partially effective in preventing subsequent IMI after a homologous live E. coli challenge. Immunization also resulted after calving in a lower linear score, lower electrical conductivity, and a higher milk production. The small size of the study warrants careful conclusions and further studies on intramammary immunization to show efficacy with heterologous challenge and eventually efficacy and safety under field conditions.

\section{ACKNOWLEDGMENTS}

The authors acknowledge the partial financial support for this study by Zoetis Animal Health as part of the Mastitis Consortium funding. Support of the staff of the Large Animal Research and Teaching Unit of the College of Agriculture and Life Sciences at Cornell University is enormously appreciated. The financial support by Agriculture and Food Research Initiative Competitive Grant no. 2015-67011-22797 from the USDA National Institute of Food and Agriculture (Washington, DC) for Brianna Pomeroy is acknowledged.

\section{REFERENCES}

Barkema, H. W., Y. H. Schukken, T. J. Lam, M. L. Beiboer, H. Wilmink, G. Benedictus, and A. Brand. 1998. Incidence of clinical mastitis in dairy herds grouped in three categories by bulk milk somatic cell counts. J. Dairy Sci. 81:411-419.

Benn, C. S., M. Netea, L. Selin, and P. Aaby. 2013. A small jab-a big effect: Nonspecific immunomodulation by vaccines. Trends Immunol. 34:431-439.

Bharathan, M., and I. K. Mullarky. 2011. Targeting mucosal immunity in the battle to develop a mastitis vaccine. J. Mammary Gland Biol. Neoplasia 16:409-419.

Blok, B. A., R. J. W. Arts, C. S. Benn, M. G. Netea, and R. v. Crevel. 2015. Trained innate immunity as underlying mechanism for the long-term, nonspecific effects of vaccines. J. Leukoc. Biol. 98:347-356.

Bradley, A. J., and M. J. Green. 2001. Adaptation of Escherichia coli to the bovine mammary gland. J. Clin. Microbiol. 39:1845-1849.

Colditz, I. G., and D. L. Watson. 1985. Humoral and cellular factors affecting the neutrophil response of the locally immunised mammary gland to staphylococcal infection. Vet. Immunol. Immunopathol. 8:107-118.
Dogan, B., S. Klaessig, M. Rishniw, R. A. Almeida, S. P. Oliver, K. Simpson, and Y. H. Schukken. 2006. Adherent and invasive Escherichia coli are associated with persistent bovine mastitis. Vet. Microbiol. 116:270-282.

Gogoi-Tiwari, J., V. Williams, C. B. Waryah, K. Y. Eto, M. Tau, P. Costantino, H. K. Tiwari, and T. Mukkur. 2015. Comparative studies of the immunogenicity and protective potential of biofilm vs planktonic Staphylococcus aureus vaccine against bovine mastitis using non-invasive mouse mastitis as a model system. Biofouling 31:543-554.

Gogoi-Tiwari, J., V. Williams, C. B. Waryah, S. Mathavan, H. K. Tiwari, P. Costantino, and T. Mukkur. 2016. Intramammary immunization of pregnant mice with staphylococcal protein A reduces the post-challenge mammary gland bacterial load but not pathology. PLoS ONE 11:e0148383.

Green, M. J., A. J. Bradley, G. F. Medley, and W. J. Browne. 2007. Cow, farm, and management factors during the dry period that determine the rate of clinical mastitis after calving. J. Dairy Sci. 90:3764-3776.

Green, L. E., M. J. Green, G. F. Medley, Y. H. Schukken, and A. J. Bradley. 2002. Influence of dry period bacterial intramammary infection on clinical mastitis in dairy cows. J. Dairy Sci. 85:25892599.

Gröhn, Y. T., D. J. Wilson, R. N. González, J. A. Hertl, H. Schulte, G. Bennett, and Y. H. Schukken. 2004. Effect of pathogen-specific clinical mastitis on milk yield in dairy cows. J. Dairy Sci. 87:3358-3374.

Gurjar, A., S. Klaessig, S. Salmon, R. Yancey, and Y. Schukken. 2013. Evaluation of an alternative dosing regimen of a J-5 mastitis vaccine against intramammary Escherichia coli challenge in nonlactating late-gestation dairy cows. J. Dairy Sci. 96:5053-5063.

Hogan, J. S., K. L. Smith, P. Schoenberger, S. Romig, and L. Thompson. 1997. Responses of antibody titers to intramammary immunization with Escherichia coli J5 bacterin. J. Dairy Sci. 80:23982402.

Hogan, J. S., D. A. Todhunter, K. L. Smith, and P. S. Schoenberger. 1992. Field trial to determine efficacy of an Escherichia coli J5 mastitis vaccine. J. Dairy Sci. 75:78-84.

Hogan, J. S., W. P. Weiss, D. A. Todhunter, K. L. Smith, and P. S. Schoenberger. 1995. Effects of an Escherichia coli J5 vaccine on mild clinical coliform mastitis. J. Dairy Sci. 78:285-290.

Jalava, K., F. O. Eko, E. Riedmann, and W. Lubitz. 2003. Bacterial ghosts as carrier and targeting systems for mucosal antigen delivery. Expert Rev. Vaccines 2:45-51.

Levine, M. M. 2000. Immunization against bacterial diseases of the intestine. J. Pediatr. Gastroenterol. Nutr. 31:336-355.

Lippolis, J. D., B. W. Brunelle, T. A. Reinhardt, R. E. Sacco, B. J. Nonnecke, B. Dogan, K. Simpson, and Y. H. Schukken. 2014. Proteomic analysis reveals protein expression differences in Escherichia coli strains associated with persistent versus transient mastitis. J. Proteomics 108:373-381.

Lubitz, P., U. B. Mayr, and W. Lubitz. 2009. Applications of bacterial ghosts in biomedicine. Adv. Exp. Med. Biol. 655:159-170.

Maeda, Y., H. Ohtsuka, M. Tomioka, and M. Oikawa. 2013. Effect of progesterone on Th1/Th2/Th17 and regulatory T cell-related genes in peripheral blood mononuclear cells during pregnancy in cows. Vet. Res. Commun. 37:43-49.

Mayr, U. B., C. Haller, W. Haidinger, A. Atrasheuskaya, E. Bukin, and W. Lubitz. 2005. Bacterial ghosts as an oral vaccine: A single dose of Escherichia coli O157:H7 bacterial ghosts protects mice against lethal challenge. Infect. Immun. 73:4810-4817.

Mayr, U. B., P. Kudela, A. Atrasheuskaya, E. Bukin, G. Ignatyev, and W. Lubitz. 2012. Rectal single dose immunization of mice with Escherichia coli $\mathrm{O} 157: \mathrm{H} 7$ bacterial ghosts induces efficient humoral and cellular immune responses and protects against the lethal heterologous challenge. Microb. Biotechnol. 5:283-294.

Oliveira, L. J., R. Barreto, F. Perecin, N. Mansouri-Attia, F. Pereira, and F. Meirelles. 2012. Modulation of maternal immune system during pregnancy in the cow. Reprod. Domest. Anim. 47(Suppl. 4):384-393. 
Paibomesai, M., B. Hussey, M. Nino-Soto, and B. A. Mallard. 2013. Effects of parturition dexamethasone on DNA methylation patterns of IFN- $\gamma$ and IL-4 promoters in CD4+ T-lymphocytes of Holstein dairy cows. Can. J. Vet. Res. 77:54-62.

Pavot, V., N. Rochereau, C. Genin, B. Verrier, and S. Paul. 2012. New insights in mucosal vaccine development. Vaccine 30:142-154.

Petzl, W., J. Günther, T. Pfister, C. Sauter-Louis, L. Goetze, S. von Aulock, A. Hafner-Marx, H. J. Schuberth, H. M. Seyfert, and H. Zerbe. 2012. Lipopolysaccharide pretreatment of the udder protects against experimental Escherichia coli mastitis. Innate Immun. 18:467-477.

Pomeroy, B., A. Sipka, S. Klaessig, and Y. H. Schukken. 2015. Monocyte-derived dendritic cells from late gestation cows have an impaired ability to mature in response to $E$. coli stimulation in a receptor and cytokine-mediated fashion. Vet. Immunol. Immunopathol. 167:22-29.

Quesnell, R. R., S. Klaessig, J. L. Watts, and Y. H. Schukken. 2012. Bovine intramammary Escherichia coli challenge infections in late gestation demonstrate a dominant antiinflammatory immunological response. J. Dairy Sci. 95:117-126.

Rosbottom, A., H. Gibney, C. Guy, A. Kipar, R. Smith, P. Kaiser, A. Trees, and D. Williams. 2008. Upregulation of cytokines is detected in the placentas of cattle infected with neospora caninum and is more marked early in gestation when fetal death is observed. Infect. Immun. 76:2352-2361.

Schukken, Y. H., J. Günther, J. Fitzpatrick, M. C. Fontaine, L. Goetze, O. Holst, J. Leigh, W. Petzl, H. J. Schuberth, A. Sipka, D. G. Smith, R. Quesnell, J. Watts, R. Yancey, H. Zerbe, A. Gurjar,
R. N. Zadoks, and H. M. Seyfert. 2011. Host-response patterns of intramammary infections in dairy cows. Vet. Immunol. Immunopathol. 144:270-289.

Schumacher, A., S. Costa, and A. C. Zenclussen. 2014. Endocrine factors modulating immune responses in pregnancy. Front. Immunol. 5:196.

Shpigel, N. Y., S. Elazar, and I. Rosenshine. 2008. Mammary pathogenic Escherichia coli. Curr. Opin. Microbiol. 11:60-65.

Sipka, A., A. Gurjar, S. Klaessig, G. Duhamel, A. Skidmore, J. Swinkels, P. Cox, and Y. Schukken. 2013. Prednisolone and cefapirin act synergistically in resolving experimental Escherichia coli mastitis. J. Dairy Sci. 96:4406-4418.

Smith, J. L., J. S. Hogan, and K. L. Smith. 1999. Efficacy of intramammary immunization with an Escherichia coli J5 bacterin. J. Dairy Sci. 82:2582-2588.

Vilte, D. A., M. Larzábal, U. B. Mayr, S. Garbaccio, M. Gammella, B. C. Rabinovitz, F. Delgado, V. Meikle, R. J. Cantet, P. Lubitz, W. Lubitz, A. Cataldi, and E. C. Mercado. 2012. A systemic vaccine based on Escherichia coli O157:H7 bacterial ghosts (BGs) reduces the excretion of E. coli O157:H7 in calves. Vet. Immunol. Immunopathol. 146:169-176.

Wilson, D. J., Y. T. Grohn, G. J. Bennett, R. N. González, Y. H. Schukken, and J. Spatz. 2008. Milk production change following clinical mastitis and reproductive performance compared among J5 vaccinated and control dairy cattle. J. Dairy Sci. 91:3869-3879.

Yuki, Y., and H. Kiyono. 2003. New generation of mucosal adjuvants for the induction of protective immunity. Rev. Med. Virol. 13:293310 . 